\title{
Trends in Kaposi's Sarcoma Survival Disparities in the United States: 1980 through 2004
}

\section{Citation}

Datta, G. D., I. Kawachi, C. Delpierre, T. Lang, and P. Grosclaude. 2010. “Trends in Kaposi's Sarcoma Survival Disparities in the United States: 1980 through 2004." Cancer Epidemiology Biomarkers \& Prevention 19 (11): 2718-26. https://doi.org/10.1158/1055-9965.epi-10-0307.

\section{Permanent link}

http://nrs.harvard.edu/urn-3:HUL.InstRepos:41275513

\section{Terms of Use}

This article was downloaded from Harvard University's DASH repository, WARNING: This file should NOT have been available for downloading from Harvard University's DASH repository.

\section{Share Your Story}

The Harvard community has made this article openly available.

Please share how this access benefits you. Submit a story.

\section{Accessibility}




\title{
Trends in Kaposi's Sarcoma Survival Disparities in the United States: 1980 through 2004
}

\author{
Geetanjali D. Datta ${ }^{1,2,3}$, Ichiro Kawachi ${ }^{1}$, Cyrille Delpierre ${ }^{2}$, Thierry Lang ${ }^{2}$, and Pascale Grosclaude ${ }^{2}$
}

\section{Abstract}

Background: Kaposi's sarcoma (KS) is the most common cancer diagnosed among people with HIV in the United States. Highly active antiretroviral therapy (HAART) is an essential treatment for KS, and recent reports document the emergence of racial disparities in KS incidence and HIV-related mortality in the postHAART era (1996 to present). The aim of this study was to examine trends in KS survival by race from the beginning of the HIV epidemic through the introduction of HAART.

Methods: Median cause-specific survival and adjusted hazard ratios for KS from 1980 to 2004 were calculated by race using Surveillance, Epidemiology, and End Results nine-area data.

Results: Median survival among both black and white patients was relatively constant until 1995 (average median survival, 14 and 18 months, respectively). In 1996, white patients experienced an increase in median survival to 103 months. In subsequent years, the increase in median survival was so great that white patients did not reach 50\% mortality (follow-up ending December 31, 2007). Survival among black patients increased gradually until its peak in 2001 when median survival had not been reached after 83 months of follow-up. However, subsequent relative decreases to 35 months occurred in 2002 and 2004.

Conclusions: The current analysis provides evidence that there have been substantial increases in KS survival among white patients in the HAART era. Black patients have also experienced some improvements but to an attenuated extent.

Impact: Careful attention should be paid to the continuing evolution of trends in KS survival and survival disparities. Cancer Epidemiol Biomarkers Prev; 19(11); 2718-26. (C2010 AACR.

\section{Introduction}

Kaposi's sarcoma (KS) is the most common cancer diagnosed among people with HIV in the United States (1) and occurs most frequently among those who are immunodeficient (2). The incidence of KS has been greatly influence by trends in the AIDS epidemic; incidence increased through the 1980 s as the AIDS epidemic spread and incidence rates declined dramatically once highly active antiretroviral therapy (HAART) was introduced in 1996 as a treatment (3-5).

In addition to being a treatment for HIV, HAART has been shown to cause regression of $\operatorname{KS}$ itself $(6,7)$ and is an essential, often exclusive, treatment for this cancer $(8$, $9)$. Recent reports document the emergence of racial dis-

Authors' Affiliations: ${ }^{1}$ Department of Society, Human Development and Health, Harvard School of Public Health, Boston, Massachusetts; 2INSERM U558, Paul Sabatier University, Toulouse, France; and ${ }^{3}$ Department of Social and Preventive Medicine, Faculty of Medicine, Université de Montréal, Montreal, Quebec, Canada

Corresponding Author: Geetanjali D. Datta, Department of Social and Preventive Medicine, Faculty of Medicine, Université de Montréal, C.P. 6128 Succursale Centre-ville, Montreal, Quebec, Canada H3C 3J7. Phone: 514-343-6111, ext. 44090; Fax: 514-343-5645. E-mail: gddatta@gmail.com

doi: 10.1158/1055-9965.EPI-10-0307

C2010 American Association for Cancer Research. parities in KS incidence and HIV-related mortality in the United States since the advent of HAART $(3,10)$. However, no known studies have explored if these disparities are reflected in survival after diagnosis with KS. Thus, the aim of this study is to examine trends in $\mathrm{KS}$ survival by race from the beginning of the HIV epidemic through the introduction of HAART.

\section{Materials and Methods}

\section{Population}

The population-based incidence and survival data from the Surveillance, Epidemiology, and End Results (SEER) nine-area public-use database (Connecticut, Detroit, Atlanta, San Francisco, Seattle, Iowa, Utah, New Mexico, and Hawaii) were used for this study. Details on the SEER program are published elsewhere (11). KS cases were coded according to the International Classification of Disease-Oncology, 2nd Edition (ICD-O2) as those with a histology code of 9140. From 1980 to 2004, 13,682 cases of KS were reported. We excluded 213 people whose cancer was ascertained from autopsy or death certificate, 503 people for whom KS was not the first cancer, 370 people with "other" race, and 125 for whom we lacked information on race. Additionally, because SEER data do not contain information on 


\begin{tabular}{|c|c|c|c|c|c|c|}
\hline & \multicolumn{3}{|c|}{ 1980-1995 } & \multicolumn{3}{|c|}{ 1996-2004 } \\
\hline & $\begin{array}{l}\text { White }(n=8,953) \\
n(\%)^{*}\end{array}$ & $\begin{array}{c}\text { Black }(n=1,030) \\
n(\%)\end{array}$ & $\boldsymbol{P}$ & $\begin{array}{c}\text { White }(n=1,179), \\
n(\%)\end{array}$ & $\begin{array}{c}\text { Black }(n=564), \\
n(\%)\end{array}$ & $\boldsymbol{P}$ \\
\hline Sex & & & $<0.0001$ & & & 0.0001 \\
\hline Male & 8,913 (99.6) & $1,003(97.4)$ & & $1,161(98.5)$ & $538(95.4)$ & \\
\hline Female & $40(0.5)$ & $27(2.6)$ & & $18(1.5)$ & $26(4.6)$ & \\
\hline Extent of disease & & & $<0.0001$ & & & 0.001 \\
\hline$T_{0}$ & $3,246(36.3)$ & $406(39.4)$ & & $573(48.6)$ & $226(40.1)$ & \\
\hline$T_{1}$ & 1,807 (20.2) & $288(28.0)$ & & $304(25.8)$ & $188(33.3)$ & \\
\hline $\mathrm{T}_{\mathrm{UK}}$ & $3,900(43.6)$ & $336(32.6)$ & & $302(25.6)$ & $150(26.6)$ & \\
\hline Age (y) & & & $<0.0001$ & & & $<0.0001$ \\
\hline$<32$ & $1,958(21.9)$ & 308 (29.9) & & $136(11.5)$ & $135(23.9)$ & \\
\hline $32-36.9$ & $2,360(26.4)$ & $289(28.1)$ & & $285(24.2)$ & $145(25.7)$ & \\
\hline $37-42.9$ & $2,461(27.5)$ & $245(23.8)$ & & 345 (29.3) & $160(28.4)$ & \\
\hline $43-64$ & $2,174(24.3)$ & 188 (18.3) & & $413(35.0)$ & $124(22.0)$ & \\
\hline Marital status & & & $<0.0001$ & & & 0.002 \\
\hline Married & 325 (3.6) & $68(6.6)$ & & $69(5.9)$ & $33(5.9)$ & \\
\hline Unmarried & $8,053(90.0)$ & $884(85.8)$ & & $942(79.9)$ & $484(85.8)$ & \\
\hline Unknown & $575(6.4)$ & $78(7.6)$ & & $168(14.3)$ & $47(8.3)$ & \\
\hline County $\%$ poverty & & & $<0.0001$ & & & $<0.0001$ \\
\hline$<5 \%$ & $84(0.9)$ & $9(0.9)$ & & $24(2.0)$ & $11(2.0)$ & \\
\hline $5-9.9 \%$ & $2,403(26.8)$ & $258(25.1)$ & & 452 (38.3) & $202(35.8)$ & \\
\hline $10-19.9 \%$ & $6,041(67.5)$ & $609(59.1)$ & & $639(54.2)$ & 261 (46.3) & \\
\hline $20 \%+$ & $191(2.1)$ & $146(14.2)$ & & $45(3.8)$ & 88 (15.6) & \\
\hline Unknown & 234 (2.6) & $8(0.8)$ & & $19(1.6)$ & $2(0.4)$ & \\
\hline
\end{tabular}

*Percentages may not sum precisely to 100 due to rounding.

HIV / AIDS status and non-AIDS-related KS tends to occur in the elderly (12), those 65 years or older $(n=745)$ were also excluded. Our analytic data set was composed of 11,726 individuals and follow-up ended on December 31, 2007 (13).

The AIDS Clinical Trials Group (ACTG) staging criteria were used for tumor risk classification. Those patients with single or multiple skin lesions were classified as having good tumor risk $\left(T_{0}\right)$. Those patients with lesions on the mucosa (e.g., oral cavity, anus, rectum, vagina, and vulva) or visceral organs (e.g., pulmonary, gastrointestinal tract, spleen, and other) alone or in combination with lesions in other areas were considered to have poor tumor risk $\left(T_{1}\right)$. Those patients with multiple lesions of nonspecific location or unknown number and location of tumors $(n=4688)$ were classified as having unknown tumor risk. The ACTG system classifies single oral tumors differently according to their nodularity and exact location. Because SEER data do not contain this information and there was the possibility of misclassification, we opted to minimize heterogeneity in the low-risk group and categorized these tumors as high risk $(n=277)$. An assessment of extent of immunodeficiency or systemic illness is not possible using SEER data; thus, we were not able to assess survival according to these factors.

\section{Covariates}

Age was divided into quartiles: $<32,32$ to $36.9,37$ to 42.9 , and 43 to 64.9 years. Marital status was categorized as married, unmarried (single, divorced, separated, or widowed), or unknown. SEER data do not include information on individual-level socioeconomic status (SES). Therefore, area-level indicators are commonly used as a general measure of SES $(14,15)$. We used the percentage of persons in the participants' county who live below the poverty line as a measure of ecologic SES. This variable was categorized as follows: $<5 \%$ poverty, $5 \%$ to $9.9 \%$ poverty, $10 \%$ to $19.9 \%$ poverty, and $\geq 20 \%$ poverty (16).

\section{Analysis}

SEER-defined cause-specific mortality was the endpoint of interest for these analyses. This includes mortality due to KS, HIV / AIDS, and several other cancer types. Details on how this classification is constructed is described elsewhere (17). Differences in the distribution of covariates according to race were assessed by conducting two-sided $\chi^{2}$ tests of association. We compared median survival times using log-rank tests to assess absolute survival differences and calculated what we will refer to as the median survival ratio (MSR = median survival among white patients/median survival among black 
patients) to assess survival differences on the ratio scale. Univariate and multivariate Cox proportional hazards models were constructed to assess the influence of covariates on racial differences in 5-year survival (followup for those diagnosed in 2003 and 2004, 2.4\% of study population, was ended at 3 and 4 years, respectively). There were very few women in our sample; therefore, although they are included in the descriptive statistics, they were not included in median survival or regression analysis.

Because we suspected that trends might be different in areas with higher KS incidence rates, but did not possess sufficient power to compare each SEER area separately, we conducted additional analysis to contrast trends between San Francisco (3) and all other SEER areas. The number of people in the lowest SES and highest SES category was small in some of the strata. Thus, we collapsed the SES variable into two categories for the Cox models $(<10 \%$ of county residence in poverty and $10 \%+$ of county residence in poverty).

\section{Results}

Before HAART (1980-1995), the distribution of sex, extent of disease, age, marital status, and ecologic SES differed according to race (Table 1). Among patients with classifiable tumors, $64.2 \%$ of white and $58.5 \%$ of black patients were diagnosed with $T_{0} \mathrm{KS}(P=0.003$, test not shown). Additionally, a larger proportion of blacks lived in counties with $>20 \%$ of their residents living below the poverty line than whites $(14.2 \%$ versus $2.1 \% ; P<0.0001$, $\chi^{2}$ test). Racial differences in all covariates were also

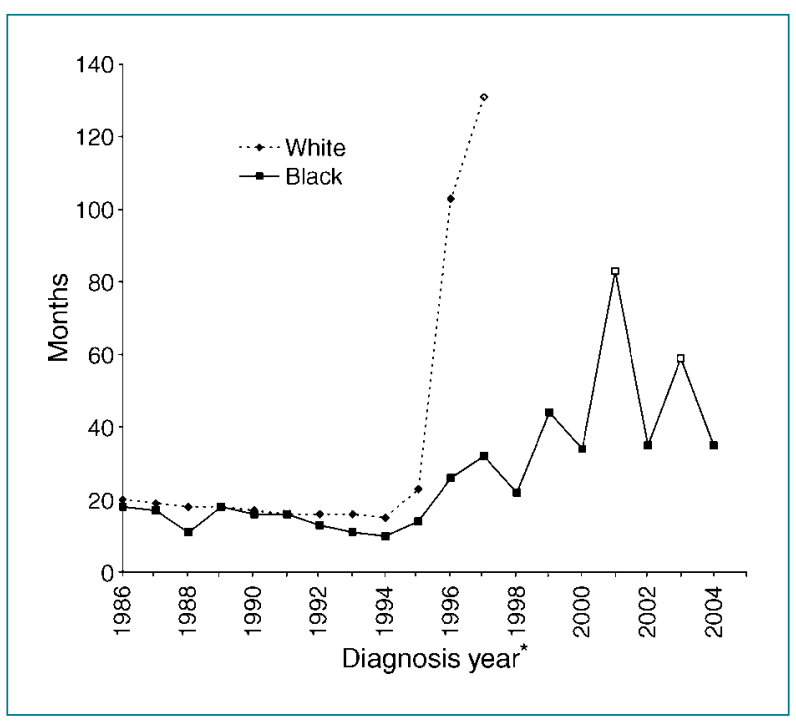

Figure 1. Median cause-specific survival by year of diagnosis. *, estimates prior to 1986 unstable because of small sample size. ${ }^{\circ}$, median survival not reached among white patients from 1997 to 2004 and among black patients in 2001 and 2003 (follow-up through December 31, 2007). observed after HAART (1996-2004). Among patients with classifiable tumors, $65.3 \%$ of white and $54.6 \%$ of black patients were diagnosed with $T_{0} \mathrm{KS}(P=0.0002$, test not shown). A significantly greater proportion of blacks than whites were diagnosed at younger than 43 years of age (78.0\% versus $65.0 \% ; P<0.0001, \chi^{2}$ test), and a greater proportion of blacks lived in counties with $>20 \%$ poverty than whites $\left(15.6 \%\right.$ versus $3.8 \% ; P<0.0001, \chi^{2}$ test).

Median survival time, the time from diagnosis at which $50 \%$ of the patients are found to be still alive, among both black and white patients was relatively constant until 1995 (Fig. 1), with white patients experiencing an average median survival of 18 months and black patients experiencing an average median survival of 14 months $(P=0.0006$; Fig. 2). In 1996, after the introduction of HAART, white patients experienced a dramatic increase in median survival from 23 months in 1995 to 103 months (Fig. 1). Median survival increased to such a great extent by 1997 that 50\% mortality was not reached in the population diagnosed in subsequent years (follow-up ending December 31, 2007). Survival among black patients increased gradually until its peak in 2001 when median survival had not been reached after 83 months of follow-up. However, subsequent relative decreases occurred in 2002 and 2004.

White and black $T_{0}$ patients experienced similar average median survival before HAART (18 versus 16 months; $P=0.77$; MSR = 1.1; Fig. 2). However, after HAART, median survival among black patients was 88 months, whereas 50\% mortality was not reached among white patients after 143 months of follow-up $(P=0.0002$; MSR $=1.6$, underestimated because median survival was not reached among white patients). Among $T_{1}$ patients, disparities in median survival were observed both before (12 versus 8 months; $P<0.0001$ ) and after HAART (76 versus 18 months; $P<0.0001)$. However, the disparities were greater on both the absolute and relative (MSR = 1.5 versus 4.3 , underestimated because median survival was not reached among white patients) scales after HAART.

Differences in median survival were observed between San Francisco and the other SEER areas combined (Fig. 3). Among $T_{0}$ patients in San Francisco, no differences in survival were observed before $(P=0.79)$ or after HAART $(P=0.31)$. In other registries, no differences were observed before HAART $(P=0.60)$. However, after HAART, significant survival differences were observed $(P=0.0004)$. Among $T_{1}$ patients in San Francisco, differences were observed before HAART $(P=0.003)$, and no significant differences were observed after HAART $(P=$ $0.15)$, although this is likely due to insufficient power. In other registries, disparities in survival among $T_{1}$ patients were evident both before and after HAART.

Univariate analysis assessing the relation between KS survival and race before HAART among $T_{0}$ patients showed no difference in hazard of mortality during the 5 years of follow-up between black and white men [hazard ratio (HR), 0.97; 95\% confidence interval (CI), 


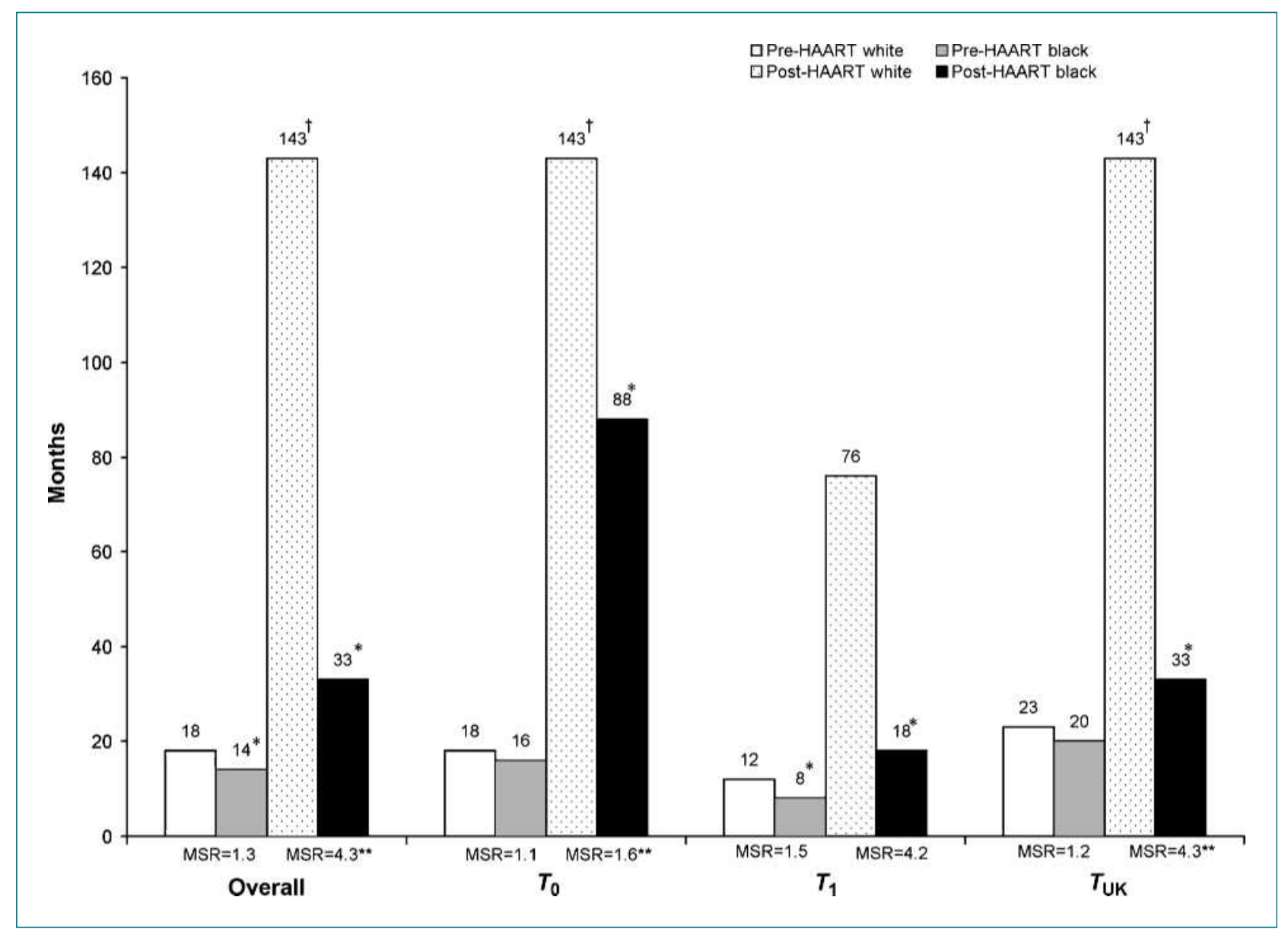

Figure 2. Median cause-specific survival time by race, tumor prognosis, and treatment era (SEER 1980-2004). ${ }^{\dagger}$, median survival not reached at 143 mo. ${ }^{*}, P<0.05 .{ }^{* *}$, underestimate, median survival not reached among white patients.

0.86-1.10; Table 2]. However, after HAART, there was a $58 \%$ increased hazard of mortality during follow-up in black men in comparison with white men (HR, 1.58; 95\% CI, 1.23-2.02). Among $T_{1}$ patients, mortality was elevated for blacks in comparison with whites both before (HR, 1.37; 95\% CI, 1.20-1.56) and after HAART (HR, 1.59; 95\% CI, 1.24-2.05).

Multivariable analysis adjusting for age, marital status, and ecologic SES yielded similar results. Among $T_{0}$ patients, no difference in survival was observed before HAART (HR, 1.00; 95\% CI, 0.88-1.13; Table 3), but a $45 \%$ increased hazard of mortality among black patients was observed after HAART (HR, 1.45; 95\% CI, 1.12-1.88) in comparison with white men. Additionally, during both periods, men who were identified as married had a significantly lower hazard of mortality than those men who were unmarried. Among $T_{1}$ patients, mortality was elevated for blacks in comparison with whites both before (HR, 1.35; 95\% CI, 1.18-1.55) and after HAART (HR, $1.52 ; 95 \%$ CI, 1.17-1.98).

Before the advent of HAART among $T_{0}$ patients, there were no observed survival disparities in San Francisco
(HR, 1.06; 95\% CI, 0.90-1.25; data not shown) or in the other SEER areas combined (HR, 0.94; 95\% CI, 0.771.13). However, after HAART, disparities emerged in other SEER areas (HR, 1.61; 95\% CI, 1.15-2.25), but no statistically significant differences were observed in San Francisco (HR, 1.13; 95\% CI, 0.71-1.81). Among $T_{1}$ patients, statistically significant disparities were observed before HAART in San Francisco and before and after HAART in other SEER areas, although the magnitude of the disparities was lower in San Francisco (before HAART: HR, 1.26; 95\% CI, 1.06-1.51; after HAART: HR, 1.18; 95\% CI, 0.74-1.90) than in other SEER areas (before HAART: HR, 1.48; 95\% CI, 1.19-1.84; after HAART: HR, 1.61; 95\% CI, 1.13-2.26).

\section{Discussion}

The study results illustrate that there has been an increase in KS survival in the HAART era. Although survival improved for both black and white men with KS after the introduction of HAART, the degree of improvement was greater for white men on both the relative and 
absolute scales. This pattern remained after accounting for tumor prognosis. The increase of a survival disparity is noteworthy, particularly because one of the United States' health goals during the time of its emergence was specifically to decrease racial disparities in health $(18,19)$.

Before the advent of HAART, treatment for KS was largely palliative (20). HAART, which promotes immune reconstitution, has been shown to cause regression of KS $(6,7)$ and is recommended either in part or in total as treatment for most KS cases $(8,9)$. Thus, increases in its availability and use are likely strong mechanisms through which KS survival has improved. In a recent study of Medicaid-insured individuals from five states, it was reported that black HIV/AIDS patients were less likely to receive HAART treatment than white patients with HIV / AIDS (21). Accordingly, one possible explanation for the increase in KS survival disparities in the HAART era is that there exist differences in the type and quality of treatment afforded to black patients in comparison with white patients.
There are several other possible explanations for the increased KS survival disparity after the advent of HAART. Initial treatment for KS with HAART is one influence on survival; however, long-term adherence to treatment may also be necessary (22). Thus, differences in treatment adherence may also partially explain differences in survival. Although HAART is an essential treatment for KS, advanced KS often additionally requires other treatments, such as chemotherapy or radiation $(9$, 23). Thus, some of the increase in disparities may be due to differences in the receipt of these treatments as well. Additionally, although we were able to account for tumor risk, we were not able to adjust by immune status or HIV-associated systemic diseases using SEER data. Therefore, there could be residual confounding of our findings by these factors.

It is interesting to note that survival disparities existed among those with poor tumor prognosis before HAART, although they were relatively small on an absolute scale in comparison with the disparities observed after HAART. The natural history of KS has changed as a

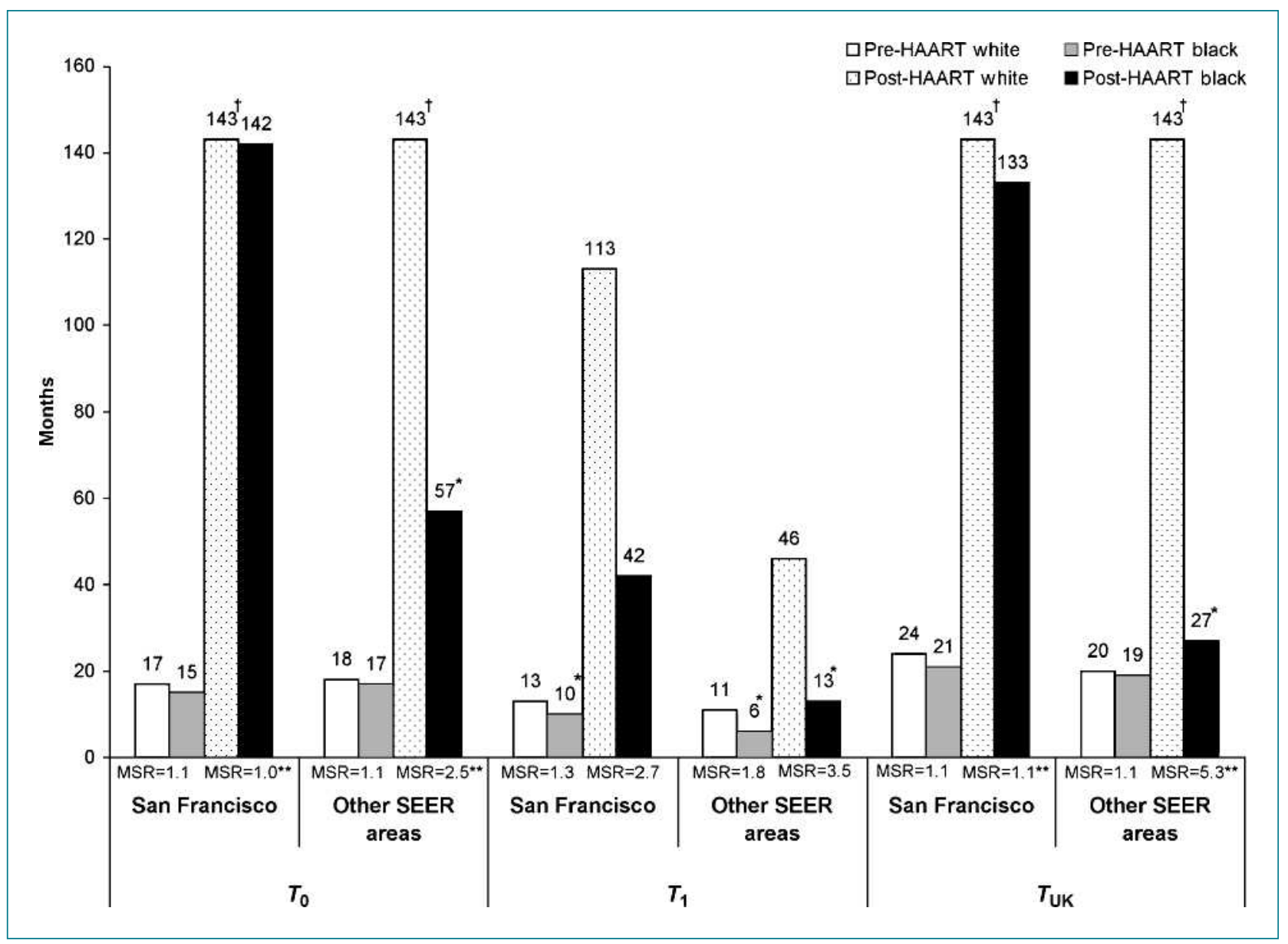

Figure 3. Median cause-specific survival time by race, tumor prognosis, treatment era, and SEER area (SEER 1980-2004). ${ }^{\dagger}$, median survival not reached at 143 mo. *, $P<0.05 .{ }^{\star \star}$, underestimate, median survival not reached among white patients. 


\begin{tabular}{|c|c|c|c|c|c|c|c|c|c|c|c|c|}
\hline & \multicolumn{4}{|c|}{$T_{0}$} & \multicolumn{4}{|c|}{$T_{1}$} & \multicolumn{4}{|c|}{$\mathbf{T}_{\mathrm{UK}}$} \\
\hline & \multicolumn{2}{|c|}{ 1980-1995 } & \multicolumn{2}{|c|}{ 1996-2004 } & \multicolumn{2}{|c|}{ 1980-1995 } & \multicolumn{2}{|c|}{ 1996-2004 } & \multicolumn{2}{|c|}{ 1980-1995 } & \multicolumn{2}{|c|}{ 1996-2004 } \\
\hline & HR & $95 \% \mathrm{Cl}$ & HR & $95 \% \mathrm{Cl}$ & HR & $95 \% \mathrm{Cl}$ & HR & $95 \% \mathrm{Cl}$ & HR & $95 \% \mathrm{Cl}$ & HR & $95 \% \mathrm{Cl}$ \\
\hline \multicolumn{13}{|l|}{ Race } \\
\hline White & 1.00 & & 1.00 & & 1.00 & & 1.00 & & 1.00 & & 1.00 & \\
\hline Black & 0.97 & $0.86-1.10$ & $1.58^{\star}$ & $1.23-2.02$ & $1.37^{\star}$ & $1.20-1.56$ & $1.59^{*}$ & $1.24-2.05$ & 1.06 & $0.92-1.21$ & $1.86^{\star}$ & $1.36-2.50$ \\
\hline \multicolumn{13}{|l|}{ Age (y) } \\
\hline$<32$ & 1.07 & $0.95-1.19$ & 1.44 & $1.00-2.09$ & 1.01 & $0.89-1.15$ & 1.23 & $0.85-1.77$ & $0.88^{\star}$ & $0.80-0.98$ & 1.23 & $0.80-1.90$ \\
\hline $32-36.9$ & 1.00 & & 1.00 & & 1.00 & & 1.00 & & 1.00 & & 1.00 & \\
\hline $37-42.9$ & 0.99 & $0.89-1.10$ & 0.95 & $0.68-1.32$ & 0.99 & $0.87-1.12$ & 0.97 & $0.69-1.37$ & 1.05 & $0.95-1.16$ & 0.94 & $0.64-1.37$ \\
\hline $43-64$ & 1.00 & $0.90-1.11$ & 0.76 & $0.54-1.06$ & 1.00 & $0.88-1.15$ & 1.06 & $0.76-1.47$ & $0.88^{*}$ & $0.79-0.98$ & 0.84 & $0.56-1.27$ \\
\hline \multicolumn{13}{|l|}{ Marital status } \\
\hline Married & $0.59^{\star}$ & $0.47-0.73$ & $0.44^{*}$ & $0.23-0.83$ & 1.09 & $0.86-1.39$ & 0.90 & $0.45-1.82$ & $0.46^{*}$ & $0.36-0.59$ & $0.28^{*}$ & $0.10-0.74$ \\
\hline Unmarried & 1.00 & & 1.00 & & 1.00 & & 1.00 & & 1.00 & & 1.00 & \\
\hline Unknown & $0.59^{\star}$ & $0.46-0.68$ & $0.58^{\star}$ & $0.37-0.92$ & $0.70^{\star}$ & $0.51-0.96$ & 0.74 & $0.38-1.43$ & $0.78^{\star}$ & $0.69-0.89$ & $0.49^{*}$ & $0.32-0.72$ \\
\hline \multicolumn{13}{|c|}{ County \% poverty } \\
\hline$<5 \%$ & 0.81 & $0.52-1.26$ & 1.67 & $0.73-3.80$ & 1.41 & $0.92-2.16$ & 1.68 & $0.78-3.64$ & 0.86 & $0.56-1.31$ & 1.02 & $0.41-2.53$ \\
\hline $5-9.9 \%$ & 1.00 & & 1.00 & & 1.00 & & 1.00 & & 1.00 & & 1.00 & \\
\hline $10-19.9 \%$ & 1.02 & $0.94-1.10$ & 0.95 & $0.74-1.23$ & 1.02 & $0.92-1.14$ & 1.07 & $0.81-1.40$ & 0.92 & $0.84-1.00$ & 1.16 & $0.84-1.59$ \\
\hline $20 \%+$ & 0.85 & $0.67-1.07$ & 1.16 & $0.74-1.82$ & 1.26 & $0.96-1.67$ & $1.85^{\star}$ & $1.13-3.01$ & 0.72 & $0.75-1.11$ & $1.64^{*}$ & $1.01-2.67$ \\
\hline
\end{tabular}

result of the advent of HAART. Before HAART, KS patients were more likely to die as a result of AIDS-related opportunistic infections, and after HAART, mortality commonly follows progression of KS (24). Thus, the finding that survival disparities existed among those with poor tumor prognosis before HAART may result from better management of HIV-related opportunistic infections among white patients before $\operatorname{HAART}(25,26)$, although heterogeneity of risk within this group may also be a partial explanation.

The current results are consistent with previous studies on related topics. A recent study by Levine et al. (10) reported that racial disparities in HIV-related mortality increased in the United States after HAART was introduced. Additionally, despite the existence of universal health care, researchers in British Columbia documented differences in the provision of HAART to those of lower SES after adjusting for clinical parameters and associated socioeconomic disparities in HIV-related mortality (27).

The analysis comparing the survival experience of those in San Francisco with those in other SEER areas yielded results that suggest that, within racial groups, men diagnosed in San Francisco have better survival than men diagnosed in other areas. The attenuation of the growth in survival disparities may be due to differences in individual-level factors, such as SES, or local factors such as greater clinical experience and expertise or a more developed public health infrastruc- ture around HIV and HIV-related disease. These findings are consistent with studies in the United States that have documented increased HAART treatment among patients who access physicians with more experience treating HIV-positive patients $(28,29)$.

There are several potential limitations to the current study. First, the data lack information on treatment with HAART. This hinders our ability to make the direct link between treatment and increased survival. However, the decrease in mortality after the introduction of HAART was dramatic to the extent that much of the trend is likely due to its availability.

KS is staged differentially than most solid tumors. The ACTG uses tumor extent, severity of immunosuppression, and the presence of HIV-associated systemic illnesses to stage KS. Unfortunately, it is not possible to assess extent of immunosuppression or systemic illness using SEER data. Thus, there may be residual confounding of the study results by these factors. However, an assessment of the ACTG staging system in the pre-HAART era suggested that tumor characteristics and immune status provide the best predictions of disease outcome (30). In contrast, an assessment of the staging system conducted in the post-HAART era concluded that tumor characteristics and systemic illness best predicted survival (24). Thus, tumor characteristics may be the most appropriate measure to use to compare survival by disease stage across treatment era. 
Another limitation is the ecologic nature of our socioeconomic measure. However, research has illustrated the importance of area-level SES in health and health outcomes $(31,32)$, and a recent study reported community-level deprivation to be a predictor of AIDS-related survival above and beyond the effect of individual-level SES in a population with universal health care coverage including free HAART treatment (33).

\section{Conclusion}

The literature on health disparities has documented that inequalities are dynamic and their magnitude can change over time. Using empirical data, researchers have shown that after the introduction of a medical innovation benefits tend to be apparent first in more advantaged groups, who have better access to care, and health disparities can widen. Over time, as innovations reach less advantaged social strata, health disparities are expected to narrow (34). However, it is not inevitable that medical innovations should lead to the emergence of disparities. Improving equal access to efficacious therapy has the potential (at least in theory) to eliminate this source of inequality.

The current data illustrate increasing KS survival disparities after the introduction of HAART, and time will tell if predicted decreases in disparities will be observed in the future. However, it is striking that after 10 years of data follow-up, black patients have yet to achieve the same level of median survival as white patients achieved in just the first year after HAART became available, especially because baseline median survival rates differed by only a few months.

In the case of disparities in infant mortality, which are influenced by the interplay between unequal social conditions and access to advances in medical care, it has been argued that an essential determinant of the relative contributions of underlying risk and health care access is the efficacy of available interventions (35). To a certain extent, this seems also to be the case for KS survival. Before efficacious treatment was available, the results of the current study suggest that KS mortality was influenced more by underlying risk than by access to medical care, although access to treatment for other opportunistic infections likely played a role. After the introduction of HAART, the contribution that access to treatment has made in survival differences seems to have increased. However, future research will be needed to evaluate what portion of the increased disparity is due to each potential cause.

The current analysis provides evidence that, in addition to previously reported reductions in KS incidence, there have also been increases in KS survival in the HAART era. It will take several more years of followup data to assess just how much median survival in

\begin{tabular}{|c|c|c|c|c|c|c|c|c|c|c|c|c|}
\hline \multirow{3}{*}{$\begin{array}{l}\text { I able 3. A } \\
1980-2004\end{array}$} & \multicolumn{4}{|c|}{$T_{0}$} & \multicolumn{4}{|c|}{$T_{1}$} & \multicolumn{4}{|c|}{$\mathbf{T}_{\mathrm{UK}}$} \\
\hline & \multicolumn{2}{|c|}{ 1980-1995 } & \multicolumn{2}{|c|}{ 1996-2004 } & \multicolumn{2}{|c|}{ 1980-1995 } & \multicolumn{2}{|c|}{ 1996-2004 } & \multicolumn{2}{|c|}{ 1980-1995 } & \multicolumn{2}{|c|}{ 1996-2004 } \\
\hline & HR & $95 \% \mathrm{Cl}$ & HR & $95 \% \mathrm{Cl}$ & HR & $95 \% \mathrm{Cl}$ & HR & $95 \% \mathrm{CI}$ & HR & $95 \% \mathrm{Cl}$ & HR & $95 \% \mathrm{Cl}$ \\
\hline \multicolumn{13}{|l|}{ Race } \\
\hline White & 1.00 & & 1.00 & & 1.00 & & 1.00 & & 1.00 & & 1.00 & \\
\hline Black & 1.00 & $0.88-1.13$ & $1.45^{\star}$ & $1.12-1.88$ & $1.35^{\star}$ & $1.18-1.55$ & $1.52^{\star}$ & $1.17-1.98$ & 1.10 & $0.95-1.27$ & $1.67^{\star}$ & $1.22-2.30$ \\
\hline \multicolumn{13}{|l|}{ Age (y) } \\
\hline$<32$ & 1.07 & $0.96-1.20$ & 1.52 & $0.66-3.50$ & 1.01 & $0.89-1.14$ & 1.09 & $0.75-1.58$ & $0.87^{\star}$ & $0.78-0.97$ & 1.04 & $0.67-1.62$ \\
\hline $32-36.9$ & 1.00 & & 1.00 & & 1.00 & & 1.00 & & 1.00 & & 1.00 & \\
\hline $37-42.9$ & 1.00 & $0.91-1.11$ & 0.90 & $0.70-1.17$ & 1.00 & $0.88-1.13$ & 0.92 & $0.65-1.31$ & 1.06 & $0.96-1.17$ & 0.93 & $0.64-1.37$ \\
\hline $43-64$ & 1.04 & $0.94-1.16$ & 0.95 & $0.60-1.51$ & 1.02 & $0.89-1.17$ & 1.06 & $0.76-1.48$ & $0.93^{\star}$ & $0.83-1.04$ & 0.99 & $0.65-1.50$ \\
\hline \multicolumn{13}{|l|}{ Marital status } \\
\hline Married & $0.59^{*}$ & $0.47-0.73$ & $0.47^{\star}$ & $0.25-0.90$ & 1.07 & $0.84-1.36$ & 0.82 & $0.40-1.66$ & $0.43^{*}$ & $0.33-0.56$ & $0.29^{\star}$ & $0.11-0.79$ \\
\hline Unmarried & 1.00 & & 1.00 & & 1.00 & & 1.00 & & 1.00 & & 1.00 & \\
\hline Unknown & $0.55^{\star}$ & $0.46-0.67$ & 0.60 & $0.38-1.21$ & $0.70^{\star}$ & $0.51-0.96$ & 0.80 & $0.41-1.58$ & $0.78^{\star}$ & $0.68-0.88$ & $0.54^{*}$ & $0.35-0.83$ \\
\hline \multicolumn{13}{|c|}{ County \% poverty } \\
\hline$<5 \%$ & 0.80 & $0.51-1.25$ & 1.66 & $0.66-4.19$ & 1.36 & $0.89-2.09$ & 1.45 & $0.67-3.16$ & 0.90 & $0.59-1.38$ & 1.01 & $0.40-2.53$ \\
\hline $5-9.9 \%$ & 1.00 & & 1.00 & & 1.00 & & 1.00 & & 1.00 & & 1.00 & \\
\hline $10-19.9 \%$ & 0.99 & $0.91-1.07$ & 0.89 & $0.66-1.19$ & 1.01 & $0.91-1.12$ & 1.05 & $0.80-1.38$ & 0.86 & $0.79-0.94$ & 1.12 & $0.81-1.54$ \\
\hline $20 \%+$ & 0.84 & $0.66-1.07$ & 0.89 & $0.52-1.53$ & 1.13 & $0.85-1.50$ & 1.56 & $0.94-2.57$ & 0.94 & $0.76-1.17$ & 1.20 & $0.72-1.98$ \\
\hline
\end{tabular}

NOTE: All variables are adjusted for one another.

${ }^{*} P<0.05$. 
white men has improved since HAART. However, black men have not enjoyed similar levels of survival increases. In fact, they have experienced relative decreases in survival in recent years. As KS is the most frequently diagnosed cancer among people with AIDS (1) and black men currently have the highest HIV incidence rate of any racial/ethnic group in the United States (36), careful attention should be paid to the evolution of KS survival trends and further research should assess whether disparities might be redressed with earlier detection and better access to or continuity of care.

\section{References}

1. Engels EA, Pfeiffer RM, Goedert JJ, et al. Trends in cancer risk among people with AIDS in the United States 1980-2002. AIDS 2006;20:1645-54.

2. In: Schottenfeld D, Fraumeni JF, editors. Cancer epidemiology and prevention. 3rd ed. Oxford: Oxford University Press; 2006.

3. Eltom MA, Jemal A, Mbulaiteye SM, Devesa SS, Biggar RJ. Trends in Kaposi's sarcoma and non-Hodgkin's lymphoma incidence in the United States from 1973 through 1998. J Natl Cancer Inst 2002;94: 1204-10.

4. Bahl S, Theis B, Nishri D, Marrett LD. Changing incidence of AIDSrelated Kaposi sarcoma and non-Hodgkin lymphoma in Ontario, Canada. Cancer Causes Control 2008;19:1251-8.

5. Grulich AE, Li Y, McDonald AM, Correll PK, Law MG, Kaldor JM. Decreasing rates of Kaposi's sarcoma and non-Hodgkin's lympho$\mathrm{ma}$ in the era of potent combination anti-retroviral therapy. AIDS 2001;15:629-33.

6. Lebbe C, Blum L, Pellet C, et al. Clinical and biological impact of antiretroviral therapy with protease inhibitors on HIV-related Kaposi's sarcoma. AIDS 1998;12:F45-9.

7. Gill J, Bourboulia D, Wilkinson J, et al. Prospective study of the effects of antiretroviral therapy on Kaposi sarcoma-associated herpesvirus infection in patients with and without Kaposi sarcoma. J Acquir Immune Defic Syndr 2002;31:384-90.

8. Di Lorenzo G, Konstantinopoulos PA, Pantanowitz L, Di Trolio R, De Placido S, Dezube BJ. Management of AIDS-related Kaposi's sarcoma. Lancet Oncol 2007;8:167-76.

9. Bernstein WB, Little RF, Wilson WH, Yarchoan R. Acquired immunodeficiency syndrome-related malignancies in the era of highly active antiretroviral therapy. Int J Hematol 2006;84:3-11.

10. Levine RS, Briggs NC, Kilbourne BS, et al. Black-White mortality from HIV in the United States before and after introduction of highly active antiretroviral therapy in 1996. Am J Public Health 2007;97: 1884-92.

11. Altekruse SF, Kosary CL, Krapcho M, et al., editors. SEER cancer statistics review, 1975-2007. Bethesda (MD): National Cancer Institute. Available from: http://seer.cancer.gov/csr/1975_2007/. Based on November 2009 SEER data submission, posted to the SEER Web site, 2010.

12. Iscovich J, Boffetta P, Franceschi S, Azizi E, Sarid R. Classic Kaposi sarcoma: epidemiology and risk factors. Cancer 2000;88: 500-17.

13. Surveillance, Epidemiology, and End Results (SEER) Program (http: //www.seer.cancer.gov) Research Data (1973-2007), National Cancer Institute DCCPS, Surveillance Research Program, Cancer Statistics Branch, released April 2010, based on the November 2009 submission.

14. Robbins AS, Whittemore AS, Thom DH. Differences in socioeconomic status and survival among white and black men with prostate cancer. Am J Epidemiol 2000;151:409-16.

15. Zell JA, Cinar P, Mobasher M, Ziogas A, Meyskens FL, Jr., AntonCulver $\mathrm{H}$. Survival for patients with invasive cutaneous melanoma

\section{Disclosure of Potential Conflicts of Interest}

No potential conflicts of interest were disclosed.

\section{Acknowledgments}

We thank Drs. Vinh-Kim Nguyen and Theresa Osypuk for providing comments on previous versions of this manuscript.

The costs of publication of this article were defrayed in part by the payment of page charges. This article must therefore be hereby marked advertisement in accordance with 18 U.S.C. Section 1734 solely to indicate this fact.

Received 03/23/2010; revised 08/03/2010; accepted 08/19/2010; published OnlineFirst 09/22/2010.

among ethnic groups: the effects of socioeconomic status and treatment. J Clin Oncol 2008;26:66-75.

16. Krieger N, Chen J, Waterman $\mathrm{P}$, Soobader M, Subramanian S, Carson R. Geocoding and monitoring US socioeconomic inequalities in mortality and cancer incidence: does the choice of area-based measure and geographic level matter? The Public Health Disparities Geocoding Project. Am J Epidemiol 2002;156: 471-82.

17. Howlader N, Ries LAG, Mariotto AB, Reichman ME, Ruhl J, Cronin KA. Improved estimates of cancer-specific survival rates from population-based data. J Natl Cancer Inst. In press 2010. First published online October 11, 2010. doi:10.1093/jnci/djq366.

18. U.S. Department of Health and Human Services. Healthy People 2000: National Health Promotion and Disease Prevention Objectives. Washington (DC): U.S. Department of Heath and Human Services; 1990.

19. U.S. Department of Health and Human Services. Healthy People 2010. 2nd ed. With Understanding and Improving Health and Objectives for Improving Health. Washington (DC): U.S. Department of Health and Human Services; 2000.

20. Morris AK, Valley AW. Overview of the management of AIDS-related Kaposi's sarcoma. Ann Pharmacother 1996;30:1150-63.

21. King WD, Minor $P$, Ramirez Kitchen $C$, et al. Racial, gender and geographic disparities of antiretroviral treatment among US Medicaid enrolees in 1998. J Epidemiol Community Health 2008;62: 798-803.

22. Lima VD, Harrigan R, Bangsberg DR, et al. The combined effect of modern highly active antiretroviral therapy regimens and adherence on mortality over time. J Acquir Immune Defic Syndr 2009;50: 529-36.

23. El Amari EB, Toutous-Trellu L, Gayet-Ageron A, et al. Predicting the evolution of Kaposi sarcoma, in the highly active antiretroviral therapy era. AIDS 2008;22:1019-28.

24. Nasti G, Talamini R, Antinori A, et al. AIDS-related Kaposi's Sarcoma: evaluation of potential new prognostic factors and assessment of the AIDS Clinical Trial Group Staging System in the HAART Era-the Italian Cooperative Group on AIDS and Tumors and the Italian Cohort of Patients Naive From Antiretrovirals. J Clin Oncol 2003;21: 2876-82.

25. Easterbrook PJ, Keruly JC, Creagh-Kirk T, Richman DD, Chaisson RE, Moore RD. Racial and ethnic differences in outcome in zidovudinetreated patients with advanced HIV disease. Zidovudine Epidemiology Study Group. JAMA 1991;266:2713-8.

26. Moore RD, Stanton D, Gopalan R, Chaisson RE. Racial differences in the use of drug therapy for HIV disease in an urban community. N Engl J Med 1994;330:763-8.

27. Wood E, Montaner JS, Chan K, et al. Socioeconomic status, access to triple therapy, and survival from HIV-disease since 1996. AIDS 2002;16:2065-72.

28. Kitahata MM, Van Rompaey SE, Dillingham PW, et al. Primary care delivery is associated with greater physician experience and 
improved survival among persons with AIDS. J Gen Intern Med 2003; 18:95-103.

29. Landon BE, Wilson IB, Mclnnes $K$, et al. Physician specialization and the quality of care for human immunodeficiency virus infection. Arch Intern Med 2005;165:1133-9.

30. Krown SE, Testa MA, Huang J. AIDS-related Kaposi's sarcoma: prospective validation of the AIDS Clinical Trials Group staging classification. AIDS Clinical Trials Group Oncology Committee. J Clin Oncol 1997;15:3085-92.

31. In: Kawachi I, Berkman L, editors. Neighborhoods and health. 1st ed. New York: Oxford University Press; 2003.

32. Datta GD, Colditz GA, Kawachi I, Subramanian SV, Palmer JR, Rosenberg L. Individual-, neighborhood-, and state-level socioeconomic predictors of cervical carcinoma screening among
U.S. black women: a multilevel analysis. Cancer 2006;106: 664-9.

33. Mari-Dell'Olmo M, Rodriguez-Sanz M, Garcia-Olalla $P$, et al. Individual and community-level effects in the socioeconomic inequalities of AIDS-related mortality in an urban area of southern Europe. J Epidemiol Community Health 2007;61: 232-40.

34. Victora $C$, Barros $F$, Vaighan J. The impact of health interventions on inequalities: infant and child health in Brazil. In: Leon DA, Walt G editors. Poverty, inequality and health: an international perspective. Oxford: Oxford University Press; 2001.

35. Wise PH. The anatomy of a disparity in infant mortality. Annu Rev Public Health 2003;24:341-62.

36. Estimates of new HIV infections in the United States. CDC HIV/AIDS facts: Centers for Disease Control and Prevention; 2008. 


\section{Cancer Epidemiology, \\ Biomarkers \& Prevention}

\section{Trends in Kaposi's Sarcoma Survival Disparities in the United States: 1980 through 2004}

Geetanjali D. Datta, Ichiro Kawachi, Cyrille Delpierre, et al.

Cancer Epidemiol Biomarkers Prev 2010;19:2718-2726. Published OnlineFirst September 22, 2010.

\section{Updated version Access the most recent version of this article at:} doi:10.1158/1055-9965.EPI-10-0307

Cited articles

This article cites 27 articles, 5 of which you can access for free at:

http://cebp.aacrjournals.org/content/19/11/2718.full\#ref-list-1

E-mail alerts Sign up to receive free email-alerts related to this article or journal.

Reprints and To order reprints of this article or to subscribe to the journal, contact the AACR Publications

Subscriptions

Department at pubs@aacr.org.

Permissions To request permission to re-use all or part of this article, use this link http://cebp.aacrjournals.org/content/19/11/2718.

Click on "Request Permissions" which will take you to the Copyright Clearance Center's (CCC) Rightslink site. 